\title{
An Overview of Sexual Assault Cases in Nepal
}

\author{
Hirachan $\mathbf{N}^{\prime *}$, Limbu $\mathrm{D}^{2}$ \\ 'Lecturer, Forensic Medicine Department, Gandaki Medical College \& Teaching Hospital, Pokhara, Nepal \\ 2MBBS, MS (Orthopedics)
}

\section{Keywords \\ Anogenital injury, Rape, Sexual abuse.}

\section{Corresponding author}

*Dr. Neelu Hirachan, MD

Lecturer, Department of Forensic

Medicine

Gandaki Medical College \& Teaching

Hospital, Pokhara, Nepal.

Email: drneeluhirachan@gmail.com

\section{ABSTRACT}

Background: Sexual assault is defined as any sexual act performed by one (or more) person(s) on another without consent. It may include the use of threat or force. In some cases, the person cannot give consent to sex because he/she is unconscious or otherwise incapacitated. A person may be raped by a stranger, an acquaintance or date or a family member.

Methods: The study was a retrospective and descriptive analysis of cases of sexual assault victims examined by the author in the Forensic Medicine departments at Institute of Medicine, Maharajgunj and Gandaki Medical College Teaching Hospital, Pokhara, Nepal over a period of four years (2012 to 2016). This includes information regarding the age group of the victim at the time of sexual abuse, relationship of the victim to the perpetrator, genital and extra-genital injuries present over the victim's body and number of cases attended as an expert witness by the author in various courts of Nepal.

Results: In the four years period, a total number of 55 cases were examined as sexual assault cases. It was observed that majority were of the 13 - 15 years of age group (46\%) followed by $<10$ years $(20 \%)$, 16 - 20 years $(16 \%),>20$ years $(11 \%)$ and $10-12$ years $(7 \%)$. Regarding the relationship of the victim to the alleged perpetrator, $87 \%$ cases (48 out of 55) were related to acquaintances compared to $13 \%$ due to strangers. Surprisingly, $3.6 \%$ cases ( 2 out of 48 ) were due to the biological fathers of the victims. On physical examination of the victim's body, $36 \%$ cases showed genital injuries compared to only $15 \%$ with extra genital injuries. The author attended the court as an expert witness in $33 \%$ of these cases. Only $7 \%$ of the cases were mentally challenged.

Conclusion: Young adults remain the most vulnerable group, so education related to sex, morality, humanity and different life skills training should be provided to these groups from their school years itself. The benefits of early intervention and comprehensive care of survivors with the use of standardized protocols along with shorter and lesser traumatic period of court processing to the survivors of these cases should be encouraged. 


\section{INTRODUCTION}

Sexual offences are very common, widespread and insidious problem that have serious physical, psychological, emotional and social consequences. An estimated one out of every three women and one out of every six men will be sexually assaulted at sometime in their life. The United States has the world's highest rape rates of all countries that publish such statistics. The U.S. rape rate is four times higher than that of Germany, thirteen times than of England and twenty times than of Japan ${ }^{1}$. Due to many related physical, mental, religious, cultural, age and social factors, only an estimated 15 - 20\% of women who have been sexually assaulted report to the police; therefore, the real incidence of sexual assault is unknown and, probably, cannot ever be accurately determined. According to the American Medical Association (1995), sexual violence is the most underreported crime. A 2007 Government report in England says that Estimates from research suggest that between 75 and $95 \%$ of rape crimes are never reported to the police ${ }^{2}$. In Nepal itself, according to the latest statistics, a woman somewhere in the country is raped every 54 minutes $^{3}$.

Sexual assault is both a common and a very serious crime which is investigated by the police with an intensity second only to that of murder ${ }^{4}$. The World Health Organization (Krug et al, 2002) defines sexual violence as any sexual act, attempt to obtain a sexual act, unwanted sexual comments or advances, or acts to traffic, or otherwise directed against a person's sexuality using coercion, by any person regardless of their relationship to the victim, in any setting including but not limited to home and work $^{5}$. It includes rape, defined as the physically forced or otherwise coerced penetration of the vulva or anus with a penis, other body part or object. Rape is a legal term. It can have devastating psychological consequences on victims, culminating in post traumatic stress disorder with an array of symptoms, including sleeping difficulties, poor appetite, flashbacks, feelings of numbness, anger, shame and denial, avoidance behavior, and relationship and sexual difficulties. In the most severe cases, depression can lead to suicidal ideation and suicide ${ }^{6}$.

In Nepal, rape is an offense, which can be committed only by man as in sexual intercourse, man is considered to take an active role rather than a woman. Anogenital injuries might have resulted due to the force used e.g. perineal tears, contusions of the labia etc. Other injuries like nail scratches, abrasions, bruises, bite marks etc can also be encountered over the various body parts. These marks of struggle constitute good corroborative evidence in favor of rape. A male of any age is considered eligible for sexual intercourse (In England, males above 14 years is only deemed to be fit). There is no definite age in a female victim for rape. However, child victims are often preferred by a rapist and reported frequently for the reasons such as they offer little resistance, they can be seduced easily, they can be threatened successfully and keep the event secret and for a "false belief" of curing the venereal diseases, as practiced in some remote villages in rural India even today $^{7}$. General code of our country i.e. Muluki Ain, rape chapter Number 1 explains that if a person enters into sexual intercourse with a woman without her consent or enters into sexual intercourse with a girl below the age of sixteen years with or without her consent shall be deemed to be an offence of rape. The $12^{\text {th }}$ amendment of the Muluki Ain has also included the marital rape as a crime and has kept three to six month punishment to the perpetrator. In the year 2013, a total of 215 women victims of rape, age more than 18 years of age, 52 cases of sexual abuse were recorded. Similarly, among 406 of minor victims of rape aged one to 17 years old, 172 cases of sexual assault were recorded ${ }^{8}$.

\section{METHODS}

The study was a retrospective and descriptive analysis of cases of sexual assault victims examined by the author in the Forensic Medicine Departments at Institute of Medicine, Maharajgunj and Gandaki Medical College Teaching Hospital, Pokhara, Nepal over a period of four years (2012 to 2016A.D.). This article includes information regarding the age of the victim at the time of sexual abuse, relationship of the victim to the perpetrator, genital and extra-genital injuries present over the victim's body and number of cases attended as an expert opinion by the author in various courts of Nepal. The data obtained were entered in microsoft excel worksheet and then analyzed. Observations were depicted in tables and graphs.

\section{RESULTS}

In the four years period, a total number of 55 cases were examined as sexual assault cases by the author. It was observed that majority were of the 13 - 15 years of age group (46\%) followed by <10 years (20\%), 16 - 20 years (16\%), >20 years (11\%) and $10-12$ years (7\%) (Fig 1). Regarding the relationship of the victim to the alleged perpetrator, $87 \%$ cases (48 out of 55 ) were related to acquaintances compared to $13 \%$ due to strangers (Fig 2). Surprisingly, $3.6 \%$ cases (Two out of 48 ) were due to the 
biological fathers of the victims. On physical examination of the victim's body, $36 \%$ cases showed genital injuries (Fig 3) compared to only $15 \%$ with extra genital injuries (Fig 4). The author attended the court as an expert witness in $33 \%$ of these cases (Fig 5). Only $7 \%$ of the cases were mentally challenged (Fig 6). Majority of the victims were unmarried $(89 \%)$ and $84 \%$ of them were educated less than tenth standard.

Fig 1: Age wise distribution of sexual abuse cases

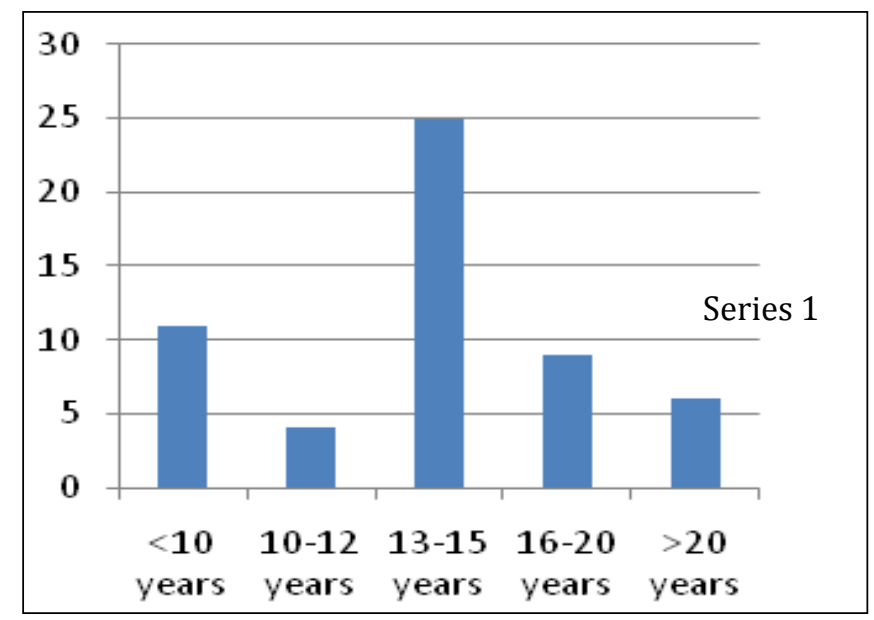

Fig 2: Relationship of the victim to the perpetrator

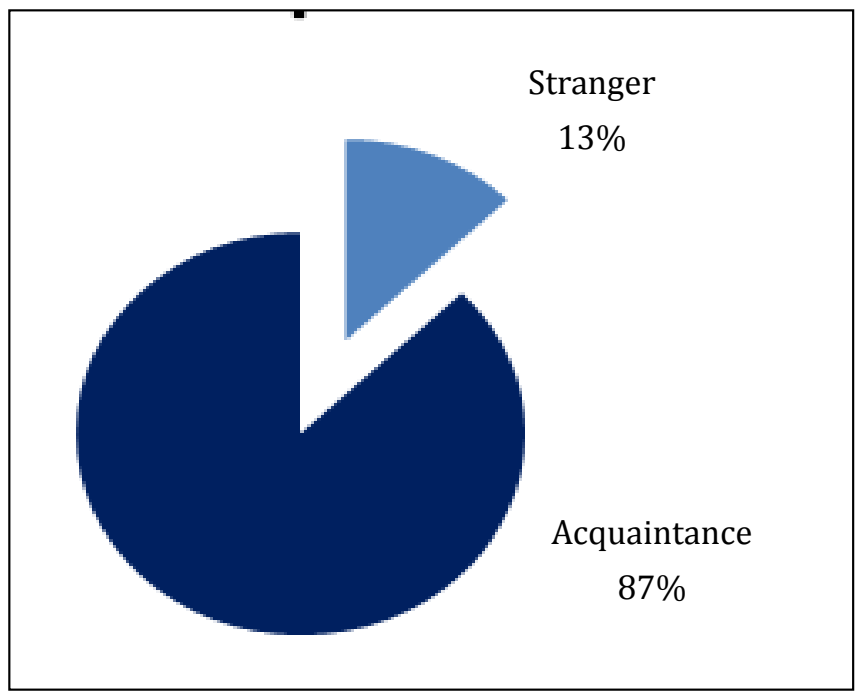

Fig 3: Extra-genital injuries in sexual abuse cases

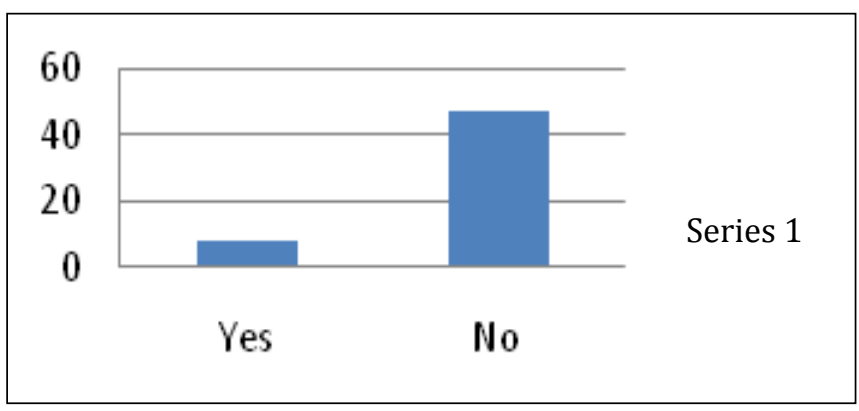

Fig 4: Genital injuries in sexual abuse cases

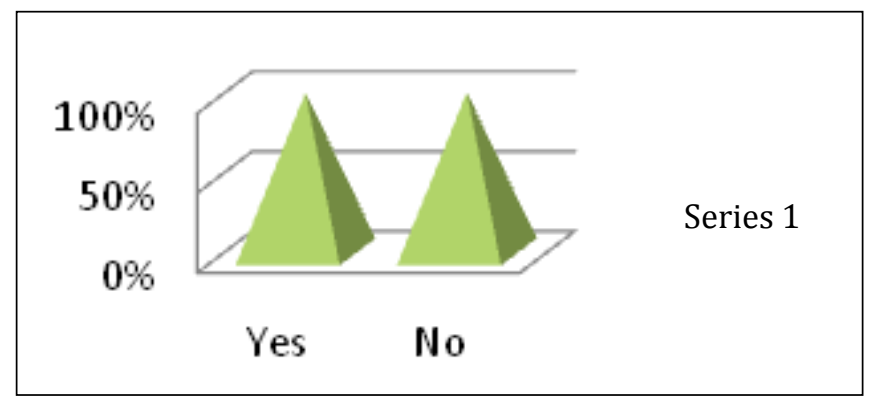

Fig 6: Mentally challenged cases

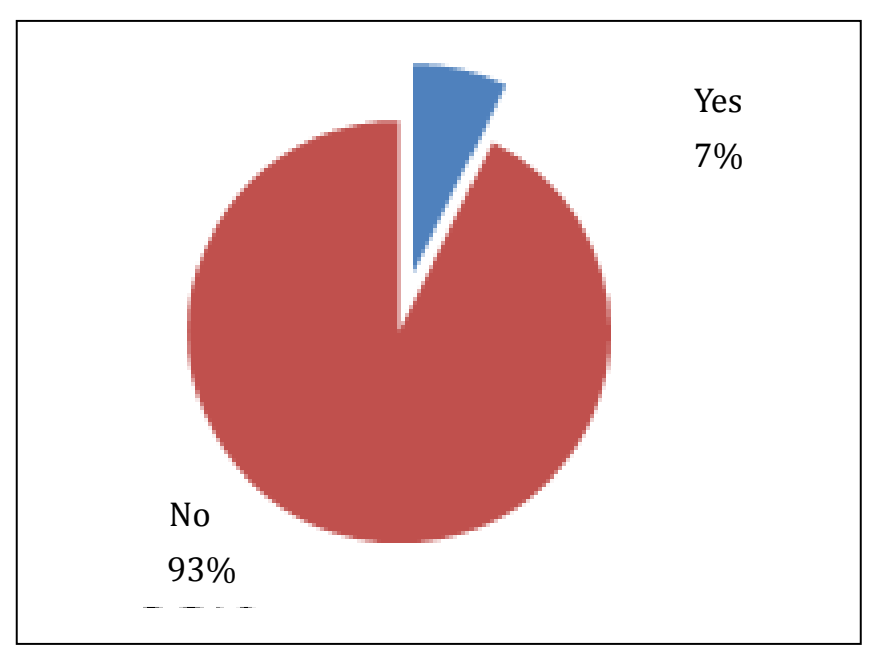

Fig 5: Court attendance as expert witness Chart

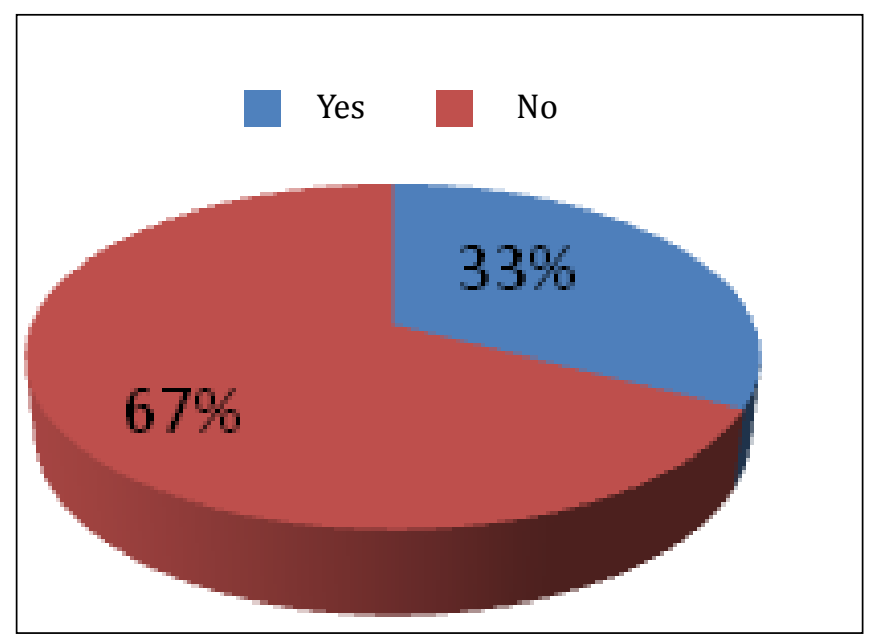

\section{DISCUSSION}

The majority of victims were of the age group $13-15$ (46\%) followed by $<10$ years (20\%), $16-20$ years $(16 \%),>20$ years $(11 \%)$ and $10-12$ years (7\%). Similar findings were given by Akinlusi et al ${ }^{9}$, Sompur SK et al ${ }^{12}$ and Palmer CM et al ${ }^{10}$. Regarding the relationship of the 
victim to the alleged perpetrator, majority were related to acquaintances (87\%) compared to strangers $(13 \%)$. Similar findings were given by Akinlusi et $a l^{9}$, Crime Records Bureau 2013 annual report of India as being 98\% of the cases committed by someone known to the victim ${ }^{11}$ and American study 1992 also gave the data of $80 \%$ of them victimized by someone they knew and national sexual violence resource center, USA stated that in eight out of ten cases of rape, the victim knew the assailant ${ }^{12}$. On physical examination of the victim's body, $36 \%$ of the total cases showed genital injuries compared to only $15 \%$ with extra genital injuries. This finding is similar to that of $20 \%$ of cases having ano-genital trauma given by Sugar NF et $a l^{13}$ and $22 \%$ cases having genital trauma given by Palmer $\mathrm{CM}$ et $a l^{10}$. The finding regarding extra-genital injuries was dissimilar to the findings given as $40 \%$ by Geist RF et $a 1^{14}, 52 \%$ given by Sugar NF et $a l^{13}$ and $46 \%$ given by Palmer CM et $a l^{10}$. The reason for this dissimilarity could be due to larger number of cases studied by these authors compared to smaller number; i.e., 55 by the author. Only $7 \%$ of the cases were mentally challenged which was dissimilar to the data shown by Cybulska B et al where $20 \%$ of the victims had history of mental health problems, self-harm or learning difficulties. This may be due to large sample size of 62081 .

\section{CONCLUSION}

Following sexual assault, victims have three main care needs: Forensic, medical and psychosocial. Doctors especially in Emergency Department must be educated and trained enough for handling, documenting and providing proper reports in cases of sexual offence. Young adults remain the most vulnerable group, so education related to sex, morality, humanity and different life skills training should be provided to these groups from their school years itself. The benefits of early intervention and comprehensive care of survivors with the use of standardized protocols along with shorter and lesser traumatic period of court processing to the survivors of these cases should be encouraged.

\section{REFERENCES}

1. Crisis Intervention Center: Sexual Assault Statistics. [Online]. Available from: http:// www.crisisinterventioncenter.org/index. php?option=com_content $\&$ view $=$ article $\& i d=67$ :sastatistics\&catid=37: sexual-assault\&Itemid $=77$
[Accessed 18 ${ }^{\text {th }}$ October 2016].

2. Wikipedia. Rape Statistics. [Online]. Available from: http://en.wikipedia.org/wiki/Rape_statistics [Accessed 20 $0^{\text {th }}$ October 2016].

3. The Women`s Foundation of Nepal: Sexual violence. [Online]. Available from: http://www.womenepal. org/index.php?option=com_content\&view=article\& $\mathrm{id}=42 \&$ Itemid $=43 \&$ lang=en $\left[\right.$ Accessed $20^{\text {th }}$ October 2016].

4. Cybulska B. Sexual assault: Key issues. J R Soc Med. 2007; 100: 321-324.

5. Krug EG, eds. (2002). World report on violence and health. Geneva, World Health Organization.

6. Petrak J, Doyle AM, Williams L, Buchan L, Foster G. The psychological impact of sexual assault: A study of female attenders of a sexual health psychology service. Sexual and Marital Therapy. 1997; 12: 33945.

7. Rao NG. Textbook of Forensic Medicine and Toxicology, 2nd edition. New Delhi: Jaypee Brothers Medical Publishers. 2010; 362.

8. Pyakurel SR. Violence against women/girls assessing the situation of Nepal in 2013. Informal Sector Service Centre (INSEC). 2014.

9. Akinlusi FM. Sexual assault in Lagos, Nigeria: A five year retrospective review. BMC Womens Health. 2014 Sep 23; $14: 115$.

10. Palmer CM, McNulty AM, D`Este C, \& Donovan B. Genital injuries in women reporting sexual assault. Sexual Health. 2004; 1(1): 55-59.

11. Vasundhara Sirnate."Good laws, bad implementation". Chennai, India: The Hindu. Retrieved 1 February 2014.

12. Sompur SK. Rape Statistics - USA [Online]. Available from:http://www.911rape.org/facts-quotes / statistics [Accessed 20 ${ }^{\text {th }}$ October 2016].

13. Sugar NF, Fine DN, Eckert LO. Physical injury after sexual assault: Findings of a large case series. Am J Obstet Gynecol. 2004; 190(1): 71-6.

14. Geist RF. Sexually related trauma. Emergency Medicine Clinics of North America. 1988; 6(3), 439-466. 